\title{
A CENTRALIDADE EM UMA CIDADE RIBEIRINHA DA AMAZÔNIA: PARINTINS-AM
}

\author{
The centrality in the riverside city of amazon: Parintins-AM
}

\author{
José Aldemir de Oliveira \\ Professor titular do Departamento de Geografia \\ Universidade Federal do Amazonas \\ jaldemir@ufam.edu.br \\ Valdilene Siqueira de Souza \\ Mestra em Geografia pela Universidade Federal do Amazonas \\ valdilene.lenesouza@gmail.com
}

\begin{abstract}
RESUMO: O entendimento da centralidade intraurbana é fundamental para identificar a importância das funções que a cidade exerce para si e para o entorno. A pesquisa que deu origem ao presente artigo consistiu em caracterizar a centralidade urbana em Parintins-AM, e descrever a influência da dinâmica do rio, identificando duas áreas de contato: a beira, na parte norte da cidade às margens do rio Amazonas e a "Lagoa da Francesa" na área interna da cidade. As pesquisas de campo possibilitaram entender que o regime hidrológico faz com que ocorra a inversão nos fluxos, a transumância urbana com o deslocamento das embarcações e, consequentemente, dos prestadores de serviços, como: vendedores ambulantes, mototaxistas, taxistas e tricicleiros, dentre outros. Esse processo contribui para a mudança da centralidade culminando no que se identificou como centralidade móvel.
\end{abstract}

Palavras-chave: Centralidade urbana; centralidade móvel; Parintins-AM.

ABSTRACT: The understanding of intracity centrality is fundamental to identify the importance of the functions that the city exercises for itself and the sorroundings. The research that gave origin to the present article consisted in characterizing the urban centrality in Parintins-AM, and to describe the influence of the dynamics of the river identifying two contact areas: the border, in the northern part of the city on the banks of the Amazon River and the "Lagoa da Francesa" in the internal area of te city. Field research has made it possible to understand that the hydrological regime causes the inversion of flows which causes urban transhumance with the displacement of the vessels and, consequently, of the service providers, such as: street vendors, mototaxistas, taxi drivers and tricicleiros, among others. This process contributes to the change of centrality culminating in what has been identified as a mobile centrality.

Key-words: Urban centrality; mobile centrality; Parintins-AM.

\section{INTRODUÇÃO}

As cidades na Amazônia não são únicas, mas estas possuem especificidades regionais relacionadas às dimensões da natureza e quase sempre o rio se constitue como o principal elemento de circulaçào fazendo com que a rede do comércio, serviço, comunicação e transporte seja influenciada por espaçotempo que apresenta dinâmica própria, pela qual, Parintins cidade ribeirinha da Amazônia se consolidou enquanto nó na rede urbana regional e a partir de fatores histórico-geográficos foi se estruturando enquanto cidade média de responsabilidade territorial por seus equipamentos urbanos exercerem funções atrativas para o entorno do próprio município e para municípios vizinhos. 
Neste artigo, privilegia-se a identificação da centralidade urbana que aponta para o movimento e dinâmica com possibilidades de encontro e reencontro de pessoas, de onde pululam ideias e conhecimento, religiosidade, sendo muito mais que o lugar das trocas de coisas e produtos, embora também seja isso. Desse modo, segue-se as ideias de Silva (2013), que considera o centro e a centralidade como denotando o mesmo sentido, no entanto apresentado diferenças. O primeiro é uma realidade material, historicamente produzida que resulta da ação convergente, ao longo do tempo, de inúmeros agentes, que a partir de suas ações individuais contribuem para a sua conformação. Já o segundo, é a capacidade de polarização, de atração e dispersão/controle dos fluxos $^{1}$ que dependem fundamentalmente da densidade de fixos ${ }^{2}$ que o centro possui.

De início é preciso considerar que a centralidade se expressa como intraurbana em decorrência da sua função para si, mas é fundamental considerar também a importância que a cidade exerce para o entorno próximo e distante, especialmente porque aqui se investiga se o rio exerce papel relevante na determinação desse processo. Desse modo, a pesquisa que originou 0 presente artigo, buscou analisar e caracterizar a centralidade urbana em Parintins-AM, e especificamente descrever a dinâmica da beira, às margens do rio Amazonas e na "Lagoa da Francesa", para identificar parâmetros de relações entre o centro e centralidade urbana e o rio, descrevendo o comércio e serviços em áreas específicas buscando caracterizá-las como centro e centralidade urbana.

Foi realizado levantamento, análise e incorporação ao texto de bibliografia sobre a temática do centro e centralidade urbana, especialmente voltada para cidades médias e pequenas. Buscou-se fontes documentais, websites, relatos, descrições e fotografias dos espaços específicos, ancorado em pesquisa sistemática com anotações no caderno de campo, instrumento essencial para compreender a paisagem urbana e a sua dinâmica.

Além das observações de campo, foram aplicados 80 formulários junto aos proprietários de embarcações em dois momentos distintos: os primeiros 40 formulários no período da vazante (meses de dezembro e janeiro de 2016), na frente da cidade onde os barcos atracam; área do mercado municipal, escadaria da Rua Rui Barbosa e rampa da Caçapava e em seguida outros 40 formulários no período da cheia (mês de maio e junho de 2016), na "Lagoa da Francesa".

Para a sistematização dos resultados se articulou de modo equanime a discussão teórica e os dados de campo, resultando na produção de gráficos, tabelas, mapas, quadros que foram completados com imagens iconográficas de épocas e do período da pesquisa juntamente com plantas da cidade.

\footnotetext{
1 "Os fluxos são um resultado direto ou indireto das ações e atravessam ou se instalam nos fixos, modificando a sua significação e seu valor, ao mesmo tempo em que, também, se modifica" (SANTOS, 2008, p.62).

2 "Os fixos são econômicos, sociais, culturais, religiosos, etc.". Eles são entre outros, pontos de serviços, pontos produtivos, casas de negócios, hospitais, casa de saúde, ambulatórios, escolas, estádios, piscinas e outros lugares de lazer [...] (SANTOS, 2007, p.142)

${ }^{3}$ Conhecida popularmente, sendo na realidade afluente do Rio Macurany.
}

REVISTA GEONORTE, V.10, N.35, p.90-107, 2019.

DOI: 10.21170/geonorte.2019.V.10.N.35.90.107

(ISSN 2237-1419) 


\section{CIDADE RIBEIRINHA DA AMAZÔNIA: PARINTINS-AM}

A cidade de Parintins situada à margem direita do rio Amazonas no Baixo Amazonas, próximo ao limite do estado do Pará, é o nó da rede urbana e é o principal centro urbano com influência às cidades de Nhamundá, Urucará, Barreirinha, Boa Vista do Ramos e Maués no Amazonas e Terra Santa, Juruti Velho e Faro no vizinho estado do Pará. Isso em parte, é possível devido à oferta de comércio e serviços urbanos que a cidade gera o que garante a circulação de embarcações que diariamente atracam na orla, vindos das cidades acima relacionadas e das agrovilas de Mocambo, Caburi, Vila Amazônia e de comunidades rurais do próprio município e dos outros municípios.

A rede urbana na Amazônia, embora com dinâmica restrita se comparada a outras regiões do Brasil, tem importância no contexto do urbano regional e se estabelece a partir de períodos econômicos pontuais, embora com precária ou mesmo ausência de infraestrutura e de serviços urbanos. Estendem-se por áreas de grandes dimensões territoriais atingindo uma população dispersa em rios e floresta, onde o rio é o entreposto comercial, o meio das relações e trocas culturais. São casos específicos das cidades ribeirinhas, onde a rede urbana ganha relevância e cristaliza no espaço certo dinamismo urbano cada vez mais concentrado em determinadas cidades. Assim é possível inferir,

\footnotetext{
Trata-se de um continuum de aglomerações urbanas-cidades ribeirinhas-, na maior parte de pequeno porte, mas importantes pelas intensas redes de trocas econômicas, culturais e sociais que se reproduzem no tempo e se espalham, por larga extensão, através do emaranhado dos cursos de água que conformam essas bacias hidrográficas organizadas a partir da referência principal que é o rio Amazonas (CASTRO; SANTOS, 2006, p. 30).
}

Desse modo, são apresentados os limites da cidade em que o rio é o marco inicial e final, a cidade começa e termina no rio, como aparece na lei n00386 de 25 de outubro de 2006, que estabelece o Perímetro Urbano da Cidade de Parintins. 


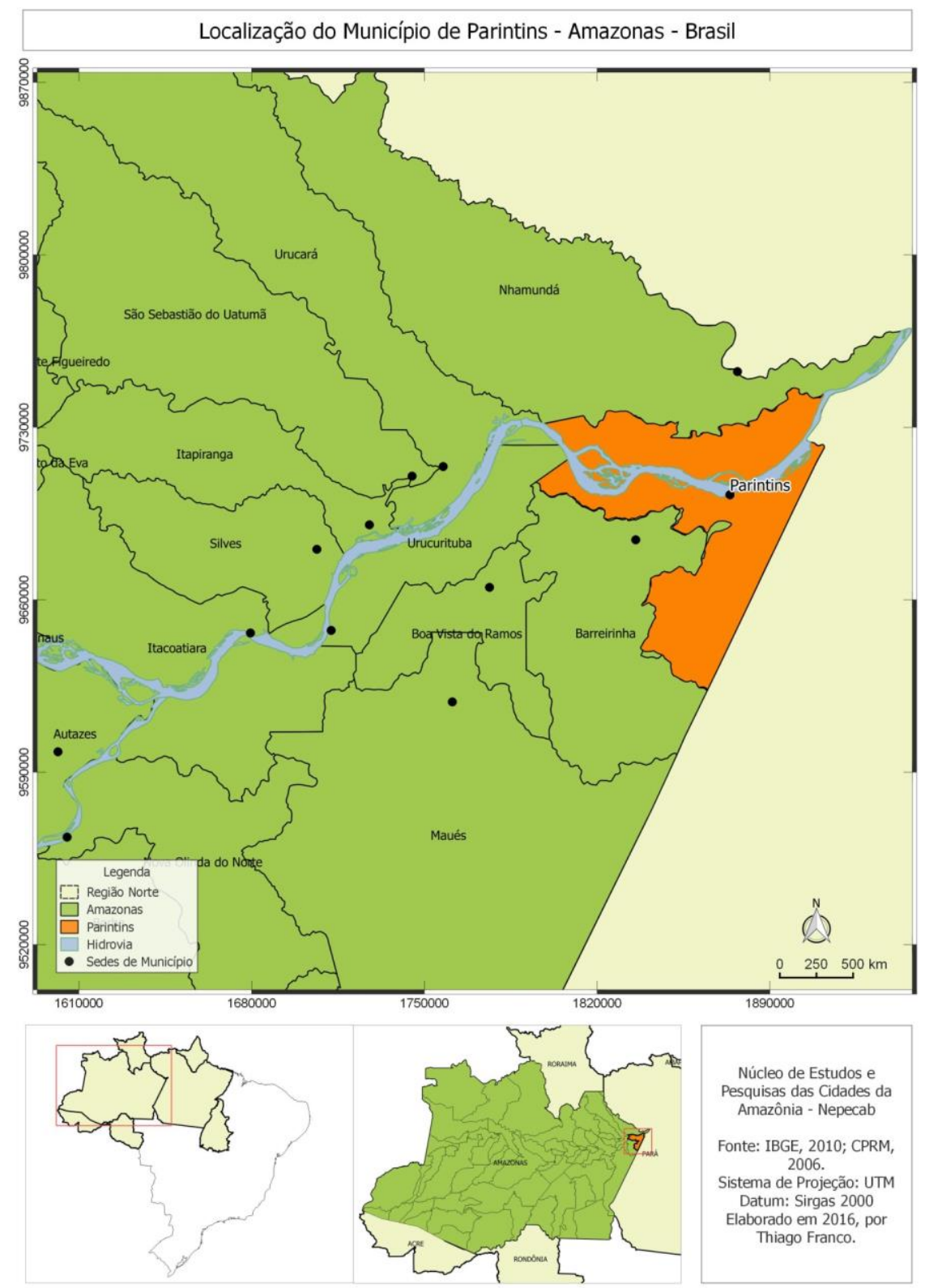

Figura 1. Localização do município de Parintins - AM.

Fonte: Google maps, 2015; CPRM, 2015; IBGE, 2010. Organizado por: Thiago Franco, 2016.

Segundo dados do Instituto Brasileiro de Geografia e Estatística (IBGE), o município de Parintins possui área territorial de $5.951,200 \mathrm{Km}^{2}$, sua população no censo 2010 do IBGE era de 102.033 habitantes no município, 67.655 na sede municipal e a estimativa de população do município para 2018 é de 113.168 habitantes (IBGE).

A classificação da cidade de Parintins como cidade ribeirinha segue Trindade Júnior, et al. (2008) que consideram à condição de pequenas cidades locais e tradicionais, como a base para conceituar estas cidades localizadas às margens dos rios na Amazônia. Porém, a dimensão da cidade ribeirinha não está apenas na sua condição de cidade beira-rio, mas por conta da dinamicidade no nível do lugar, pelas articulações socioeconômicas e culturais 
que mantêm na escala geográfica local e regional que traduzem estreita relação com o rio.

Desse modo, Parintins assume posição como cidade ribeirinha, mais que isso, é uma ilha e apresenta certa dinâmica urbana decorrente do oferecimento de serviços públicos e privados e do comércio, apresentando processo de crescimento urbano nas últimas décadas. Exerce função de centralidade urbana em relação aos municípios próximos, que se caracteriza por uma centralidade interurbana móvel influenciada pelo regime hidrológico que está relacionado à cheia dos rios que a rodeiam iniciando em janeiro e vai até junho e à vazante que inicia em julho e vai até dezembro.

A centralidade principal está na beira, a beira do rio, que dá dinâmica no ir e vir. A frente da cidade, denominada pelos moradores, é a área que contorna, media o contato do rio com a cidade, que é a ligação da cidade com o mundo, próximo e distante. A Orla de Parintins, expressa nos documentos oficiais, é cada vez mais restrita, sendo composta por espaços particulares de residências, armazéns, palafitas, portos (marinas) e chácaras. O pouco de espaço público, no sentido de acesso para todos, são as vias públicas (pontas de ruas), rampas, praças com escadarias que estão se perdendo com a ocorrência das terras caídas ${ }^{4}$, na área da frente da cidade por onde o Rio Amazonas passa com a sua imponência.

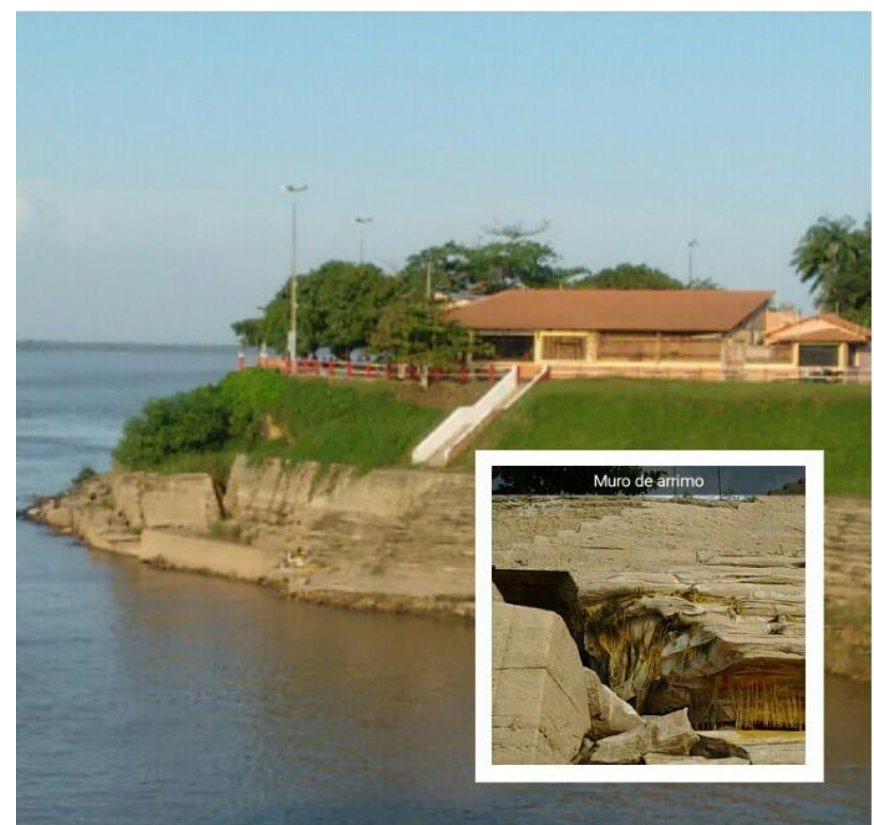

Figura 2. Muro de arrimo na orla da cidade, em Parintins-AM.

Foto: Valdilene Siqueira, trabalho de campo, 2016.

A circulação de mercadorias que abastecem as prateleiras do comércio local é feita exclusivamente pelo rio por meio de embarcações de diferentes tamanhos

\footnotetext{
${ }^{3}$ Um termo regional amazônico usado principalmente para designar erosão fluvial acelerada que envolve desde os processos mais simples a altamente complexos, englobando indiferenciadamente escorregamento, deslizamento, desmoronamento e desabamento [...] (CARVALHO, 2006, p. 55).
} 
que chegam diariamente no cais do porto e em portos privados, vindas principalmente de Manaus, como: eletrodomésticos, e alimentos industrializados que são transportados nas balsas e embarcações de cargas e passageiros, suprindo a demanda de material de construção, gás de cozinha, combustível, entre outros.

Os produtos regionais e locais chegam das áreas rurais próximas e distantes para abastecer feiras e pequenos comércios de produtos regionais que fazem parte da mesa da população local, vindos em pequenas embarcações que além dos produtos (agrícolas, extrativos, peixes, pequenos animais) trazem e levam pessoas, pois essas pequenas embarcações, ao retornarem levam produtos industrializados e beneficiados que abastecem as localidades do município e do entorno. Estes barcos, a maioria construídos de madeira de propriedade de pequenos agricultores ou criadores, dificilmente transportam somente passageiros ou produtos. Recentemente surgem as lanchas rápidas, que prioritariamente transportam pessoas especialmente de cidades e vilas próximas.

Parintins é uma e ilha e como tal, o principal fluxo de transporte de grande curso, especialmente com a cidade de Manaus, é mesmo o fluvial, por meio de barcos de recreio e lanchas rápidas. Há também a via aérea com voo diário entre Manaus e Santarém. As passagens aéreas são restritivas, os preços são considerados elevados para a maioria da população, principalmente no período de festas. O transporte aéreo, que poderia ser alternativa de deslocamento rápido, além do custo, sofreu outrora com constantes interrupções por conta da existência do lixão nas cercanias do aeroporto, um problema existente por vários anos e cuja solução é sempre postergada.

A movimentação da economia no município foi permeada por ciclos econômicos, aparecendo a partir da crise da borracha, a introdução da cultura da juta pelos japoneses na década de 1930 (CORRÊA, 2006), quando municípios do médio e baixo Amazonas, como Parintins e Itacoatiara no Amazonas, tornaram-se importantes locais de produção e as respectivas cidades, centros de beneficiamento de juta, sobretudo, pelas indústrias paulistas de sacaria destinada à embalagem de café para a exportação. No caso específico de Parintins, há ainda a pecuária que se torna importante do ponto de vista regional e a pequena agricultura de várzea. Todos estes fatores estavam ligados à economia rural em entram em crise nos anos de 1970 e determinam o processo de crescimento da cidade que tem a partir dos anos de 1980, o Festival Folclórico como festa capturada pela indústria cultural que ao crescer atrai para cidade vários equipamentos urbanos, especialmente educação superior e com isso aumenta a demanda por serviços que vão determinar a atual estrutura da cidade.

No papel de Parintins na dinâmica da rede urbana regional e local há papel relevante do comércio. Na análise de Salgueiro e Cachinho (2009) as relações entre a cidade e o comércio são dinâmicas e fundadoras de relações em ambos os sentidos. As práticas de comércio que englobam a circulação o consumo resultam em práticas espaciais, onde a cidade torna-se o suporte às ações desenvolvidas pelos diferentes sujeitos envolvidos no processo. Neste sentido, a cidade é o próprio processo. 
A evolução do ponto de vista econômico e espacial geram mudanças na sociedade com transformações de valores e estilos de vida que vão influenciar a evolução dos aglomerados e as metamorfoses da estrutura urbana. Dessa forma, as pequenas cidades na Amazônia são inseridas no circuito das trocas comerciais que se modificam no tempo e no espaço. São relações que ainda permanecem, mas tendenciam a se transformarem, antes eram as "cadernetas do fiado" que anotavam as contas a serem pagas no final do mês ou no final do fábrico, hoje substituídas pelo crediário da loja, pelo cartão de crédito e até pelas compras na internet. Tudo isso facilitado pelo avanço das telecomunicações que atingem a periferia nos rincões da Amazônia num processo de "modernização incompleta", visto que é restritiva, pois não muda a estrutura da sociedade, continuando precário o acesso aos serviços portadores de cidadania como educação, saúde e segurança.

Parintins apresenta a mesma realidade de outras cidades com precariedade de acesso à equipamentos urbanos não tão presentes no interior ${ }^{5}$, porém é estereotipada por muitos, como um lugar de magia e da beleza, assim como a Amazônia, descrita por Browder e Godfrey (2006, p. 19), "As metáforas descrevendo a Amazônia são tipicamente monumentalistas e ilusórias". Parintins é vendida por seu Festival Folclórico e o que se reproduz na mídia, e até reforçado por seus moradores, "é a ilha da magia, terra do folclore, terra de artista, terra do boi bumbá", no entanto, o que se vivencia é outra realidade, distante da que ocorre no Festival Folclórico, como se tudo fosse organizado para funcionar durante três dias.

As contradições que estão na lógica de como a cidade se produz são parte da centralidade urbana, que se de um lado, é influenciada pelo regime hidrológico, de outro, também o é, pelas dimensões culturais, pela importância socioeconômica que gera dinamicidade do comércio e dos serviços que resultam do festival. Tais aspectos não são estanques, mas complementares e articulados, embora aqui se trate de compreender a espacialidade decorrente da dinâmica de um aspecto natural - o rio.

\section{CENTRALIDADE NUMA CIDADE RIBEIRINHA DA AMAZÔNIA: PARINTINS- AM}

A cidade de Parintins, assim como outras cidades passa por modificações na paisagem urbana e no modo de vida com influência nas formas e funções do espaço. Torna-se necessário conhecer e entender os processos de permanências e rupturas presentes na cidade e como a centralidade se modifica em diferentes épocas especialmente relacionada aos períodos de cheia e vazante do rio e os lugares que comportam a centralidade.

A primeira área observada foi a "beira", a "frente", a área de contato do rio Amazonas com a cidade e a segunda a Lagoa da Francesa localizada na área interna da cidade. Observou-se que nas duas áreas a centralidade quase não ocorre em concomitância, uma como que elimina a outra, sendo por isso

\footnotetext{
${ }^{5} \mathrm{Na}$ Amazônia a ideia de campo não se assemelha a de outras regiões do Brasil, onde o campo é floresta, rio e terra. Neste sentido, utilizaremos o termo conforme o texto "Relações cidade e campo na Amazônia: as trocas materiais e imateriais" de Maurício Adu, (2016).
}

REVISTA GEONORTE, V.10, N.35, p.90-107, 2019.

(ISSN 2237-1419) 
denominada de "centralidade móvel", porque ocorrem em tempos diversos e com dinâmicas próprias. Embora não se trate de espaço metropolitano, seguese o que foi apontado por Ana Fani A. Carlos, de que,

\begin{abstract}
Os momentos de produção do espaço geram centralidades diferenciadas em função do deslocamento do comércio, dos serviços e do lazer. Essas transformações decorrentes das funções dos lugares da cidade geram o que chamo de 'centralidades móveis' movimentação no espaço metropolitano de centros geradores de fluxo assentadas nas novas formas de comércio e dos serviços modernos (CARLOS, 2007, p.15 - grifos meus).
\end{abstract}

No caso de Parintins, estamos falando de uma cidade média com especificidade de centralidade que pode ocorrer em função da dinâmica do rio, e essa inversão modifica os fluxos do urbano, mas não gera modernização no comércio e serviços que parecem ser cristalizados no espaço. Na literatura é mais comum discorrer sobre a centralidade nas grandes metrópoles e nas cidades médias, visto que nas cidades pequenas esse fator urbano é pouco estudado, por que a centralidade não se constitui com grande dinamicidade, se trata mais de inércia comparada ao que ocorre nas metrópoles. Logo, estamos de acordo como Olanda, para quem

\begin{abstract}
[...] a discussão sobre centralidade é pouco expressiva no que diz respeito às cidades pequenas, uma vez que essa temática tem sido mais trabalhada pelos geógrafos para análises dos espaços intraurbanos das cidades médias e das metrópoles (OLANDA, 2010, p. 141).
\end{abstract}

Mas tal reconhecimento não tira a importância da análise do tema especialmente quando se trata das cidades amazônicas. É importante mostrar que a dinâmica urbana na cidade de Parintins está relacionada à sazonalidade dos rios, como já apontado antes, durante os meses de julho a dezembro é o processo de descida das águas - o período da vazante. De janeiro a junho o período de cheia do rio. Trata-se de um processo natural contínuo, que ocorre com maior ou menor intensidade, de cheia ou de vazante, todos os anos e acarreta a mudança do fluxo de pessoas em decorrência da dinâmica do comercio e de serviços de uma área à outra da cidade.

$\mathrm{Na}$ vazante a maioria das embarcações atraca na beira, na frente da cidade, enquanto outras atracam durante 0 ano todo independente do período. Segundo Carvalho (2012), o regime hidrológico do rio Amazonas, resulta fundamentalmente do regime pluviométrico irregular tanto temporal quanto espacial, mas de qualquer modo a amplitude hidrológica, a diferença entre a maior e a menor cheia ou vazante não são significativos.

\footnotetext{
Registros diários do regime hidrológico no porto de Manaus [...] mostram que 0 rio Amazonas começa a subir em novembro/dezembro e vai até junho/julho. Já a vazante começa em julho/agosto e vai até outubro/novembro. Verifica-se que o rio leva de seis a sete meses subindo e desce em apenas quatro a cinco meses. Por tanto, o tempo de vazante é bem menor do que o tempo de enchente (CARVALHO, 2012, p. 52-53).
} 
$\mathrm{Na}$ cheia as embarcações atracam na área da "Lagoa da Francesa" e em outros pontos da cidade, Souza (2013, p. 68) enfatiza que na "década de 1990, os principais pontos comerciais da cidade estavam localizados na Rua João Melo, com acesso a Rampa do Mercado Municipal; e na Francesa com acesso à "Lagoa da Francesa"'. Fato que comprova que nestas duas áreas, o centro e a centralidade se dão a partir da dinâmica do rio.

O sítio da cidade é um arquipélago entrecortado por furos e pequenos canais fluviais. As relações sociais de produção faz com que o homem se adeque as suas necessidades de mobilidade e permanências. No caso de Parintins pelo fato do sítio estar numa ilha, há ajustamentos quanto aos espaços de moradia e acessibilidade. A partir do crescimento da cidade e a necessidade de conexão e deslocamento ao núcleo central, os gestores municipais iniciaram um trabalho de aterramento das vias de ligação no trecho da "Ponte do Gabião" na Rua Paraíba, na "Ponte da cidade Garantido ou Ponte da Fabril" que dá acesso a Rodovia Odovaldo Novo e aeroporto, "Ponte Amazonino Mendes" que interligam os bairros de Itaúna, Paulo Corrêa e União a outras áreas da cidade. Com o crescimento da cidade e o aumento populacional, o espaço urbano ganha amplitude, desse modo, o centro da cidade permanece, mas as novas centralidades, ou a velha centralidade ganha novos significados.

No caso de Parintins, o centro ainda é visto como lugar mais importante, e mais atrativo para a população, pois ainda concentra maior número de atividades relacionadas ao comércio e serviços. Mas já não é lugar de morar da elite local, perde esta função para as áreas de expansão e para a beira do rio onde se concentram as mansões.

Todavia o centro ainda mantém, "(...) as atividades comerciais e de serviços dão visibilidade às centralidades que são criadas ou redefinidas" (GARCEZ, 2009, p. 101), e as duas áreas identificadas como centralidade são contíguas ou muito próximas do centro. Neste sentido, a cidade cristaliza ao longo do tempo, o seu crescimento onde sua estruturação aparecerá nas formas e nas funções as quais demandam intensa articulação com outros lugares por seu grau de importância.

Assim, conforme estudos feitos em outras cidades brasileiras,

A centralidade é a relação entre os espaços com maior densidade de meios de consumo, coletivos, individual, e o que representam esses espaços em termos de valor histórico e simbólico, bem como as possibilidades de se ter acesso a eles. Essas perspectivas levam-nos a associar o centro às localizações, e a centralidade, aos fluxos que afluem ao centro e dele efluem, assim como as representações que sobre essas áreas se constituem (SPOSITO; GÓES, 2013, p. 121).

A centralidade pode ser influenciada pelo deslocamento de pessoas, a facilidade ou a dificuldade para tal. $O$ acesso a determinados fatores da modernização poderão diminuir o deslocamento de pessoas ao centro, podendo contribuir para a diminuição dos fluxos. No entanto, em Parintins estes fatores são incipientes e restritos e o centro continuará a ser o lugar de atração de pessoas, garantindo a permanência do comércio e dos serviços. Os 
dados da pesquisa demonstram que é possível o surgimento de outros centros, porém o centro ligado ao rio que permanece enquanto local da dinamicidade da cidade ribeirinha.

\title{
A DINÂMICA DO RIO E A CENTRALIDADE MÓVEL: "LAGOA DA FRANCESA" E BEIRA DA CIDADE
}

No contexto da cidade ribeirinha na Amazônia há espaços diferenciados por peculiaridades locais que podem se assemelhar com outras áreas, podendo ser similares, mas nunca iguais. Um desses espaços urbanos de Parintins é a popularmente conhecida "Lagoa da Francesa" que foi sendo modificada ao longo do tempo. As ações do poder público possibilitaram o melhoramento urbanístico e com isso atraiu moradores, comerciantes, e habitantes de outros lugares da cidade que foram produzindo novas espacialidades que resultaram na configuração atual. Dessa forma, o que ocorreu na Lagoa da Francesa é o processo identificado por Milton Santos nos

\begin{abstract}
Movimentos da sociedade, atribuindo novas funções às formas geográficas, transformam a organização do espaço, criam novas situações de equilíbrio e, ao mesmo tempo, novos pontos de partida para um novo movimento. Por adquirirem uma vida, sempre renovada pelo movimento social, as formas - tornadas assim forma-conteúdopodem participar de uma dialética com a própria sociedade e assim fazer parte da própria evolução do espaço (SANTOS, 2014, p.106).
\end{abstract}

Por exemplo, foi graças à alteração no padrão de drenagem que fez com que a "Lagoa da Francesa" adquirisse a configuração atual, conforme afirmação do geógrafo e professor da UFAM José Alberto Lima de Carvalho:

\begin{abstract}
A Francesa não é lagoa nem lago, e sim um afluente do Rio Macurany, denominado popularmente também como "Lago do Macurany", que do ponto de vista conceitual é um rio, que durante esse processo também sofreu alterações devido à interceptação do seu fluxo. Mesmo cortado no seu curso superior, o Macurany não deixou de ser um rio, ainda que tenha sido parcialmente bloqueado. $A$ Francesa, portanto, sendo um antigo afluente do Macurany, é um canal com padrão dendrítico e de primeira ordem (entrevista concedida em janeiro de 2017).
\end{abstract}




\section{dy' REVISTA GEONORTE}

Lagoa da Francesa - Águas Altas e Águas baixas
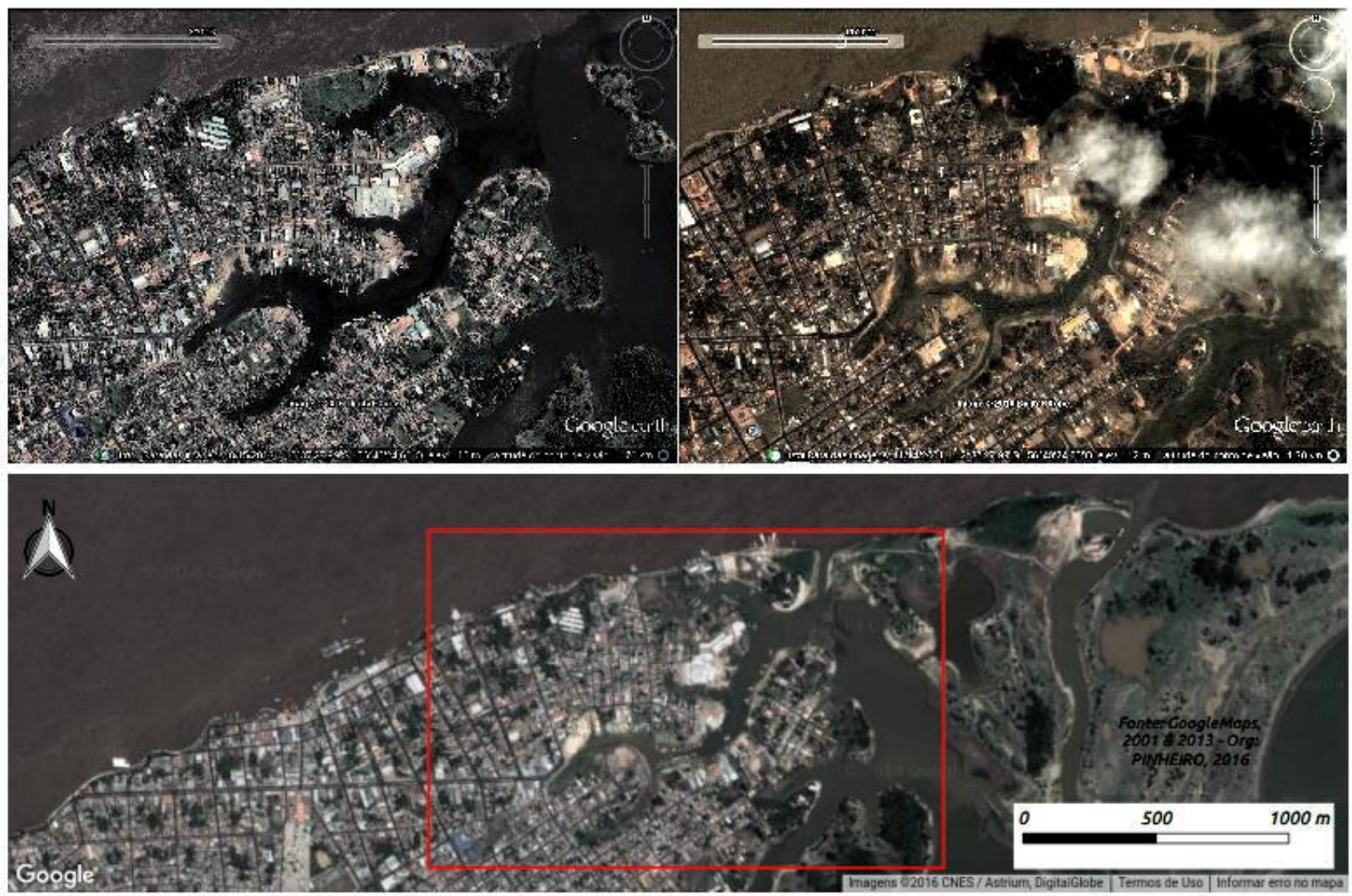

Figura 3. Sazonalidade na Lagoa da Francesa em Parintins-AM.

Fonte: Imagens de satélite: Google Maps. Organizado por: Estevan Bartoli, 2017.

Nota-se que a centralidade das embarcações em frente à cidade ocorre durante todo o ano com maior incidência na vazante e menor proporção na cheia, como retrata Ribeiro Filho "o ciclo anual de enchentes e vazantes rompem a relativa monotonia da região e cria novas paisagens, diferentes, fazendo com que o homem se ajuste às variações dos níveis das águas" (2011, p. 74).

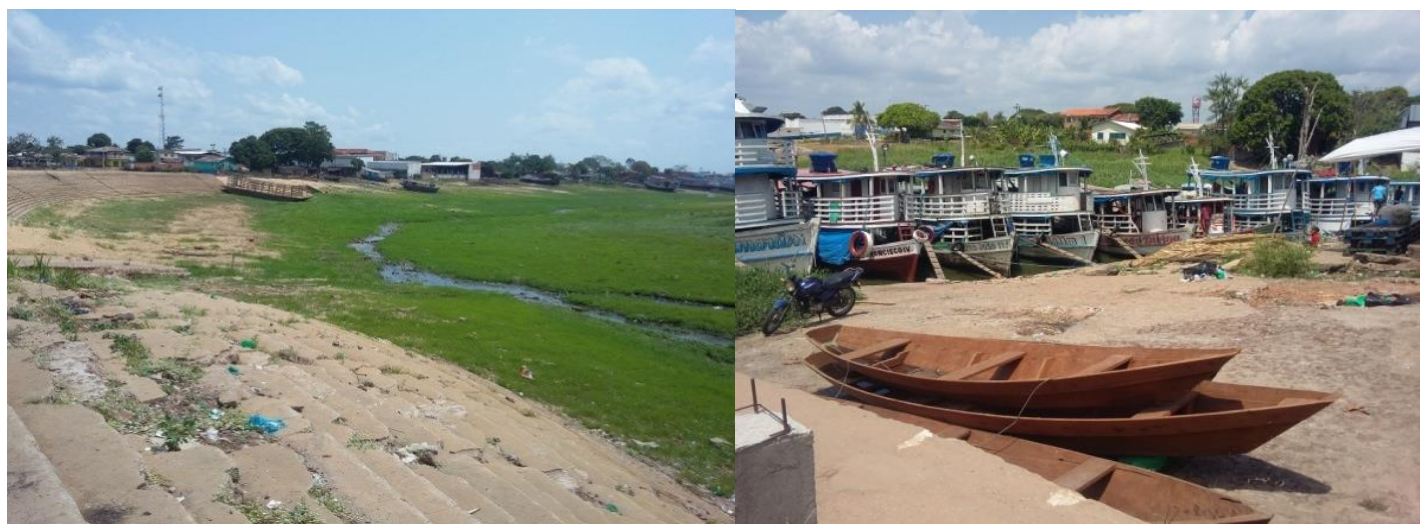

Figura 4 e 5. Escadaria da Francesa na vazante e cheia.

Foto: Valdilene Siqueira, trabalho de campo, 2016. 
$\mathrm{Na}$ pesquisa de campo, quando da aplicação dos formulários, os donos das embarcações foram indagados onde atracavam suas embarcações no período da enchente, 68\% responderam na Lagoa da Francesa, 29\% na rampa do mercado e proximidades, e $3 \%$ no porto da baixa do São José, o que demonstra certa permanência de embarcações na frente da cidade.

Todavia, o maior fluxo é na Lagoa da Francesa, fazendo com que a área se tornasse espaço para comércios e poucas indústrias quase sempre ligadas a serviços de reparos e oficinas de barcos. A área do entorno da Lagoa e formada pelos bairros de Santa Clara, Francesa, Castanheira e Santa Rita de Cássia. No período da cheia de janeiro a junho aumenta o fluxo de embarcações e pessoas, o comércio e os serviços tornam-se mais dinâmicos no local, mostrando que,

\begin{abstract}
A cidade, em seu tecido urbano, se apresenta dividida através da produção de uma desigual disposição de fenômenos nas suas distintas parcelas, engendrando uma articulação interna que tende a se configurar de forma diferenciada e segmentada. Desta forma, estabelecem-se espaços na cidade que dispõe de uma maior concentração de atividades que concebem a esses espaços um maior poder de articulação. Assim, estes espaços exercem atração sobre as demais parcelas do tecido urbano e constituem uma centralidade urbana, que compreende também uma área capaz de gerar e manter fluxos (de pessoas, capitais e mercadorias, etc.) e não apenas concentrar determinados fixos (OLIVEIRA JR., 2008, p. 68).
\end{abstract}

Na paisagem urbana, as embarcações que ancoram no local, diariamente dão dinâmica ao espaço, embarcando e desembarcando pessoas, mercadorias e bens materiais e imateriais, e com isso observa-se também outras atividades como o serviço de moto-táxi, carreto em triciclos 6 , o trabalhador avulso e uma rede de trabalhos, uns legais e outros nem tanto, tais atividades se desenrolam no local.

Ainda na pesquisa, foi constatado que, $74 \%$ dos entrevistados fazem compras na área da Lagoa da Francesa, percentual que mostra a dinâmica local no período da cheia quando há maior concentração de embarcações. Esse movimento se estende para o entorno, provando que há intensa troca entre produtos do interior e da cidade, embora, no período ocorra a diminuição da oferta de produtos agrícolas em decorrência das cheias dos rios.

$\mathrm{Na}$ entrevista com lojistas, as respostas quanto ao período de maior movimento mostraram o aumento na cheia e a diminuição na vazante. Os trabalhadores ambulantes (mototaxistas e tricicleiros), disseram que migram acompanhando o ritmo das águas, na cheia na Lagoa da Francesa, na vazante na frente da cidade. Essa dinâmica mostra que a "redefinição da centralidade é acompanhada por processos de descentralização e de recentralização, que movimentam fixos e fluxos e atribuem novas dinâmicas ao espaço urbano" (SILVA, 2006, p. 215).

\footnotetext{
6 "Esse modal é composto por uma estrutura originária da bicicleta acrescida de uma cabine geralmente coberta na frente, onde é possível fazer o transporte tanto de passageiro como de cargas e o que for possível caber no veículo" (LEITE et al. 2015, p. 203).
}

REVISTA GEONORTE, V.10, N.35, p.90-107, 2019.

(ISSN 2237-1419) 
Conforme a água baixa, as embarcações, os flutuantes, as relações comerciais e os fluxos vão saindo da Lagoa da Francesa e se dirigem para outros lugares da cidade. Essa área é a beira ou a frente da cidade onde a cidade principia, sendo o rio o seu limite. É o lugar de entrada e de saída de pessoas, das mercadorias vindas de longe e de produtos agrícolas de perto. Portanto a beira para a população e a orla nos documentos oficiais, "diz respeito ao espaço imediato de interação entre terra e água, seja considerando os rios de maiores dimensões, seja considerando os igarapés" (TRINDADE JUNIOR, et al., 2005, p. 13), é uma movimentação cotidiana intensamente vivenda pela população local, mas que passa despercebida pelos que chegam apenas para usufruir dos equipamentos urbanos.

No período da vazante anualmente há a acumulação de sedimentos do Rio Amazonas na frente da cidade, dessa forma inicia-se a formação de uma praia temporária no mês de agosto, dando outra dinâmica a essa área da cidade, o que pôde ser comprovado durante a aplicação de formulário na cheia na "Lagoa da Francesa". Por meio de levantamento de dados foi possível constatar que no período da vazante, $53 \%$ das embarcações atracam na rampa do mercado, $47 \%$ na rampa da Caçapava, ou seja, a totalidade utiliza-se da beira para atracar.

Alguns entrevistados citaram que eventualmente procuram outros portos para atracar, sendo citados: o Porto do Hospital Jofre Cohen, próximo a rampa da Caçapava, e Escadaria da Rua Rui Barbosa, os donos das embarcações buscam áreas mais acessíveis para aportar.

Aqui aparece um problema recorrente nas cidades amazônicas: a apropriação das margens dos rios. De acordo com Trindade Júnior, et al. (2008) quanto à discussão das janelas e portas para o rio, em Parintins existem apenas pequenas frestas abertas pela centralidade móvel, nesse caso a rampa do Mercado Municipal, a escadaria da Rua Rui Barbosa e a rampa da Caçapava. O que seriam essas frestas? São portos improvisados que não tem estrutura adequada para servir a população. São as pequenas passagens que a centralidade móvel abre para o contato da "beira" com o centro da cidade, a área do comércio e serviços, pois a frente da cidade foi apropriada "ganhou seus proprietários", os donos de bares, restaurantes e residências.

Em decorrência, "apesar de, desde sempre, o transporte fluvial se constituir no principal meio de circulação na Amazônia, o porto para embarque e desembarque de pessoas em barcos de pequeno porte sempre foi improvisado e precário" (SANTANA; SCHERER, 2009, p. 221). O desembarque é feito ao acaso, mas a dinâmica, a circulação de pessoas e mercadorias deixam despercebido esses aspectos na paisagem.

Nem portos nem trapiches, ou portos para outra realidade. Estes locais improvisados são frestas da centralidade e mostra a falta de infraestrutura em toda sua extensão da beira. Não se percebe a presença do Estado, e nota-se a ausência de políticas públicas em cuidar de um elo de dinamicidade entre 0 interior e a cidade. Muitos moradores da várzea, da terra-firme e cidades próximas dependem desses pequenos espaços para irem em busca dos serviços urbanos que embora com precariedade, ainda é a cidade que oferece. 
As obras até então dispostas ao longo da orla, não contemplam a adequação para o embarque e desembarque, com a construção do muro de arrimo, os espaços e as calçadas próximas foram ocupadas. Nota-se, a dificuldade no embarque e desembarque em pedaços de madeira improvisados: as pranchas; ou o malabarismo de barco em barco para ter acesso à rua. Podemos avaliar esse aspecto, na descrição a seguir de como se chega às cidades da Amazônia:

\begin{abstract}
Finalmente, chega-se e ancora-se na beira do rio, em algo como porto, cais ou trapiche, quase sempre improvisado, em que tudo é transitório. A improvisação do local onde param os barcos dá a quem chega a impressão de que nas cidades ribeirinhas da Amazônia nada é perene, tudo é temporário, inacabado e precocemente deteriorado. Este local aonde se chega e se vai contém a possibilidade do entendimento da cidade, pois a vida começa no porto, menos pelo movimento, mas pelo fato de ele encerrar quase tudo que a cidade possui e que nela falta. $O$ porto ou como o chamemos é o intermédio entre o rio e a floresta, e a cidade é a fronteira de diferentes mundos e nos possibilita várias leituras de espaços-tempos diversos (OLIVEIRA \& SCHOR, 2008, p.15).
\end{abstract}

Há em Parintins o porto oficial, porém os barcos que permanecem nesse local pagam para usufruir da atracação, assim como as marinas para lanchas particulares. Alguns espaços da frente da cidade se fecharam para dar lugar a postos de gasolina, a portos particulares que descarregam tijolos, areia, cimento, gás de cozinha e outros materiais que abastecem os depósitos do comércio dos maiores empresários da cidade.

Durante pesquisa de campo o que se pode constatar é que, do ponto de vista da Prefeitura responsável pela organização e funcionamento do porto, há diferenças de acesso e infraestrutura em relação ao terminal de transporte fluvial voltado para os turistas, para os que vêm de fora visitar a cidade, pois estes não podem e não devem acessar o rio nas mesmas condições que o morador ou o visitante regular do interior da região. O estacionamento do porto torna-se o lugar do reencontro dos viajantes e o lugar da diversão das famílias que também utilizam o seu estacionamento como espaço de lazer.

Nota-se que a maioria das embarcações (60\%) aporta na Rampa do Mercado, um dos fatores deve-se a proximidade da Rua João Melo e o entorno como área comercial e a localização das agências bancárias da cidade. Foi constatado junto aos donos das embarcações que há delimitação entre a Escadaria da Rua Rui Barbosa e a Rampa do Mercado, e que convenciona o atraque das embarcações nesses locais; os barcos de pesca e descarga de outras matérias-primas têm prioridade de aporte na Escadaria e as embarcações da zona rural e dos municípios próximos, na Rampa.

Desse modo, há mudança, mesmo que esta seja quase imperceptível, as cidades se renovam e ao mesmo tempo cristalizam determinadas atividades em seu espaço. O centro ou núcleo urbano já não consegue dar conta de uma estrutura em crescimento. A tendência é que ocorram novas centralidades, estas talvez não guardem mais as especificidades do lugar, como no caso em análise em que se verificou que as centralidades ocorrem de maneira peculiar, influenciada pelo regime de cheia e vazante do rio.

REVISTA GEONORTE, V.10, N.35, p.90-107, 2019.

(ISSN 2237-1419) 
Contudo, Parintins é uma cidade ribeirinha que mantêm uma estreita relação com o rio, havendo complementaridade com a dinâmica do urbano que reflete nos fluxos que ora se invertem. O que temos em Parintins é o rio como principal meio de entrada e saída e de troca entre o interior e a cidade e da cidade com outras cidades. Ao mesmo tempo permite o encontro e a festa, seja das áreas rurais ou urbanas dos municípios próximos e da capital, onde as pessoas confraternizam se reencontram ou se despedem.

O que se delineou é uma cidade do rio onde a paisagem com as formas e dinâmicas criam relações de trocas não apenas de produtos e coisas, mas também propiciado o encontro das pessoas. Há também sinais dos grandes centros urbanos, tais como o consumo do espaço e o espaço do consumo que se imbricam para a apropriação do público em benefício do privado, os bares com suas mesas, cadeiras e atendentes circulando, a música ao vivo, dinamizam e vendem a natureza como o meio e fim.

\section{CONCLUSÃO}

Primeiramente o estudo da centralidade numa cidade ribeirinha foi desafiador, visto que a mesma aparenta possuir uma dinâmica quase estática se comparada aos grandes centros urbanos, mas que para a presente proposta foi possível verticalizar o estudo da centralidade, nas dimensões das cidades médias de outras regiões do país. O desafio é buscar as centralidades onde aparentemente estas não estão presentes, no caso, a cidade de Parintins.

Dessa forma, a pesquisa procurou compreender a centralidade em ParintinsAM, o recorte espacial possibilitou o estudo da sede municipal, como contribuição ao estudo do urbano na Amazônia, considerando a centralidade a partir do regime hidrológico.

As pesquisas de campo possibilitaram sustentar que o regime hidrológico faz com que ocorra a inversão nos fluxos, onde anualmente há uma transumância urbana, verificada pelo deslocamento principal das embarcações e, consequentemente de vendedores ambulantes, mototaxistas, taxistas e tricicleiros o que contribui para a mudança da centralidade culminando, no que se denominou de centralidade móvel.

$\mathrm{Na}$ vazante a frente da cidade se torna a centralidade plena, visto que durante o ano independente de cheia ou vazante as embarcações das agrovilas de Mocambo, Caburi e cidades próximas como Nhamundá e Barreirinha, utilizam principalmente a Rampa do Mercado Municipal, Escadaria da rua Rui Barbosa e Rampa da Caçapava para atracação e o porto principal com movimentação o ano inteiro.

Outro fator a ser considerado é a diferença de tratamento entre o porto principal e a porto de atracação regional. Durante a pesquisa de campo, foi evidenciado pelos donos das embarcações e passageiros, a falta de investimento na infraestrutura para atracação, embarque e desembarque, visto que a movimentação de carros e motocicletas de supermercados, triciclos e carregadores com mercadorias é constante, superando todos os entraves de acesso até a embarcação, da mesma forma, ocorre para os passageiros que trazem suas bagagens e produtos regionais para os atravessadores. 
$\mathrm{Na}$ cheia, a centralidade se redimensiona para a parte sul da cidade. O Rio Macurany com sua cota hidrológica suficiente, abriga embarcações em diferentes áreas da cidade, mas a Lagoa da Francesa, afluente desse rio, se destaca devido a dinâmica na Escadaria, a circulação de pessoas, as trocas econômicas, o aumento do consumo nas lojas do entorno, o encontro, a conversa, uma área plana e acessível para o embarque e desembarque, todos são elementos que dinamizam a paisagem e revelam a extrema ligação da cidade com o rio. Os resultados indicam que as embarcações atracam nesse local por estar próximo ao comércio e segurança para a embarcação, sendo que a maioria atraca na parte norte da cidade, por não ter outra opção.

Desse modo, a cidade ribeirinha não deve ser negada, pois o rio é o entreposto da cidade, fator da conectividade entre cidades, agrovilas e comunidades do entorno, e que as permanências apontam para um perfil urbano com qualidade de vida, onde o setor primário merece atenção, mas o que temos são padrões de vida impostos pelo sistema capitalista, administrado de acordo com interesses privado.

Estas cidades não podem ser vistas apenas como lugares de perda, mas como potencialidades que muitas vezes foram ou são renegadas, ou até mesmo desconhecidas por seus próprios moradores que mantêm um ideal de cidade, onde permanecem pequenas "frestas para a centralidade" que são articuladas entre si, não sendo isoladas, visto que suas dinâmicas determinam interrelações com a proximidade dos fixos ao movimento de pessoas e a circulação de mercadorias.

\section{REFERÊNCIAS}

BROWDER, J. O. GODFREY, B. J. Cidades da floresta: urbanização, desenvolvimento e globalização na Amazônia Brasileira. Trad. Gisele Vieira Goldstein com colaboração de Joscilene Souza. 1. ed. Manaus: EDUA, 2006. $384 \mathrm{p}$.

CARLOS, A. F. A. O espaço urbano: Novos escritos sobre a cidade. São Paulo: FFLCH, 2007. $123 \mathrm{p}$.

CARVALHO, J. A. L. Terras caídas e consequências sociais: Costa da Miracauera, Paraná da Trindade, Município de Itacoatiara-AM, Brasil. Dissertação (Mestrado em Sociedade e Cultura na Amazônia) - Universidade Federal do Amazonas-UFAM, Manaus. 2006. $142 \mathrm{f}$.

CARVALHO, J. A. L. Erosão nas margens do Rio Amazonas: o fenômeno das terras caídas e suas implicações na vida dos moradores. Tese (Doutorado em Geografia) - Universidade Federal Fluminense, Rio de Janeiro. 2012. $187 \mathrm{f}$.

CASTRO, E; SANTOS, M. A. Belém de água e de portos: ação do Estado e modernização na superfície. In: CASTRO, E. (org.). Belém de águas e ilhas. Belém: CEJUP, 2006. p. 25 - 43 
CORRÊA, R. L. Estudos sobre a Rede Urbana. Rio de Janeiro: Bertrand Brasil, 2006.

GARCEZ, K. M. G. Centro e Centralidade em São Luiz do Maranhão. Dissertação (Mestrado em Geografia) - Programa de Pós-Graduação em Geografia. Universidade Estadual Paulista "Júlio de Mesquita Filho", Câmpus de Presidente Prudente. 2009. $123 \mathrm{f}$.

IBGE. Instituto Brasileiro de Geografia e Estatística. Censos Demográficos: 1970, 1980, 1990, 2010. Rio de Janeiro, IBGE, 2014. Disponível em: http://ibge.gov.br/. Acesso: ag. 2016.

IBGE. Instituto Brasileiro de Geografia e Estatística. Cidades.IBGE. Disponível: https://cidades.ibge.gov.br/brasil/am/parintins/panorama. Acesso: nov.2018.

LEITE, A.; CAMILO, E. A.; SCHOR, T. Barco, moto, bicicleta: deslocamentos intra-urbanos nas cidades de Itacoatiara e Parintins/AM. In: SCHOR, T.; SANTANA, P. V. (Orgs.). Dinâmica Urbana na Amazônia Brasileira. Manaus: Editora Valer, CNPQ, Fapeam, 2015. (Coleção Geografias e Cidades, Vol. II) p. $185-213$

OLANDA, E. R. Sanclerlândia-GO: do povoado do Cruzeiro às novas centralidades. Tese (Doutorado em Geografia) - Faculdade de Ciência e Tecnologia, Universidade Estadual Paulista, Presidente Prudente. 2010. 208 f.

OLIVEIRA JUNIOR, G. A. Novas Expressões de Centralidade e (re)produção do espaço urbano em cidades médias: O Jequitibá Plaza Shopping em ItabunaBA. Dissertação (Mestrado em Geografia), Universidade de Brasilia, Departamento de Geografia, Brasilia. 2008. 383 f.

OLIVEIRA, J. A.; SCHOR, T. Das cidades da natureza à natureza das cidades. In: TRINDADE JUNIOR, S. C.; TAVARES, M. G. C. (orgs.). Cidades Ribeirinhas na Amazônia: mudanças e permanências. Belém: EDUFPA, 2008. p. $15-26$

PARINTINS. Lei Municipal no 0386, de 19 de dezembro de 2006. Dispõe sobre Perímetro Urbano do Município de Parintins e dá outras providências.

RIBEIRO FILHO, V. Novas centralidades em Manaus. In: OLIVEIRA, J. A. (org.). Espaços Urbanos na Amazônia. Visões Geográficas. Manaus: Editora Valler, 2011.

SALGUEIRO, T. B., CACHINHO, H. As relações cidade-comércio. Dinâmicas de evolução e modelos interpretativos. In: CARRERAS, C.; PACHECO, S. (orgs.). Cidade e comércio: a rua comercial na perspectiva internacional. Rio de Janeiro: Armazém das Letras, 2009. p.9- 39

SANTANA, L. H.; SCHERER, E. Trabalho e ambiente no caos do cais da Manaus Moderna. In: OLIVEIRA, J. A.; SCHERER, E. Amazônia: território, 
povos tradicionais e ambiente. Manaus: Editora da Universidade do Estado do Amazonas, 2009. p. 220 - 247

SANTOS, M. A natureza do Espaço: Técnica e tempo, razão e emoção. 4.ed. 8. reimpr. São Paulo: Editora da Universidade de São Paulo, 2014. 384 p.

SANTOS, M. O espaço dividido: os dois circuitos da economia urbana dos países subdesenvolvidos. São Paulo: Edusp, 2008.

SANTOS, M. O espaço do cidadão. São Paulo: Edusp, 2007.

SCHWADE, M. A. Relações cidade e campo na Amazônia: trocas materiais e imateriais. In: OLIVEIRA, J. A de. Dinâmica urbana na Amazônia brasileira: espacialidades, ambiente e saúde. Manaus: EDUA, 2016. p. 93 -120 (v.4)

SILVA, O. T. da. Conceito de centro e centralidade como um instrumento de compreensão da realidade urbana. In: XIII SIMPÓSIO DE GEOGRAFIA URBANA. UERJ. Rio de Janeiro. 18 a 22 novembro de 2013. p. 1 - 18

SILVA, W. R. Para além das cidades: Centralidade e Estruturação Urbana: Londrina e Maringá. Tese (Doutorado em Geografia) - UNESP/Campus Presidente Prudente. Faculdade de Ciência e Tecnologia, Universidade Estadual Paulista, Presidente Prudente. 2006. $280 \mathrm{f}$.

SOUZA, N. D. O processo de urbanização da cidade de Parintins-AM: evolução e transformação. Tese (Doutorado em Geografia) Faculdade de Filosofia, Letras e Ciências Humanas, Universidade de São Paulo, São Paulo. 2013. 155 f.

SPOSITO, M. E.; GÓES, E. M. Espaços fechados e cidades Insegurança urbana e Fragmentação socioespacial. 1.ed. São Paulo: Editora Unesp, 2013. $365 \mathrm{p}$.

TRINDADE JUNIOR., S. C; SILVA, M. A. P.; AMARAL, M. D. B. Das "janelas" às "portas" para os rios: compreendendo as cidades ribeirinhas na Amazônia. In: TRINDADE JUNIOR., S. C. C; TAVARES, M. G. C. (orgs.). Cidades ribeirinhas na Amazônia: mudanças e permanências. Belém: EDUFPA, 2008. p. $27-47$

TRINDADE JUNIOR., S. C.; SANTOS, E. R. C. RAVENA, N. A cidade e o rio: espaço e tempo na orla fluvial de Belém. In: TRINDADE JUNIOR., S. C. C.; SILVA, M. A. P. (Orgs.). Belém: a cidade e o rio na Amazônia. Belém: Editora da EDUFPA, 2005. p. $12-43$

Recebido em 02/03/2019 Aceito em 01/08/2019 